\title{
O BIOGRAMA COMO REFERENCIAL TEÓRICO- METODOLÓGICO PARA CONSTRUÇÃO DE TRAJETÓRIA DE VIDA-CIENTÍFICA NA EDUCAÇÃO MUSICAL
}

\section{RAIMUNDO VAGNER LEITE DE OLIVEIRA}

https://orcid.org/0000-0003-2079-6619

Universidade de Brasília

O presente texto é uma síntese de uma pesquisa concluída de mestrado cuja temática incidiu sobre trajetória de vida-científica de pesquisadores da área da Educação Musical. Os pressupostos teóricos foram embasados em conceitos de trajetórias de vida. A metodologia utilizada foi de natureza qualitativa, com base na pesquisa documental cuja fonte incidiu sobre o Currículo Lattes usado para preencher o biograma. O foco deste texto é apresentar um novo formato de biograma além de mostrar de que modo ele foi utilizado como referencial teórico-metodológico. Os dados aqui apresentados são excertos desse foco. A trajetória de vida-científica é o recorte de uma vida inteira que faz referência à atuação no campo da Educação Musical. Os resultados revelam que o biograma pode ser considerado como referencial teórico-metodológico. É teórico por trazer o conceito de biograma para o campo da Educação Musical e metodológico por ser o instrumento usado para a construção das trajetórias de vida-científica. É um modo de dar vida ao Currículo Lattes e visibilidade às trajetórias de vidacientíficas pela valoração - resultado da interpretação. Conclui-se que ao analisar os registros no biograma foi possivel representar, por sua unidade e coerência, a trajetória de vida-científica como um encadeamento que enreda uma história de vida com a Educação Musical. Palavras-chave: Educação Musical. Trajetória de vida-científica. Biograma.

\section{ABSTRACT BIOGRAM AS THEORETICAL-METHODOLOGICAL REFERENCE FOR CONSTRUCTION TRAJECTORY OF SCIENTIFIC-LIFE IN MUSIC EDUCATION}

This text is a synthesis of a completed master's research whose theme focused on the trajectory of the scientific life of researchers in the 
area of Music Education. The theoretical assumptions were based on concepts of life trajectories. The methodology used was qualitative in nature, based on documentary research whose source focused on the Lattes Curriculum used to fill out the Biogram. The focus of this text is to present how the Biogram was used as a theoretical-methodological framework. The data presented here are excerpts from this focus. The trajectory of scientific-life is the cutout of a lifetime that refers to the performance in the field of Music Education. The results reveal that the Biogram is a type of methodologically instrumentalizing. It is theoretical for bringing the concept of Biogram to the field of Musical and methodological Education because it is the instrument used for the construction of trajectories of scientific-life. It is a way of giving life to the Lattes Curriculum and visibility to the trajectories of life-scientific by valuation - a result of interpretation. It is concluded that by analyzing the records in the Biogram it was possible to represent, by its unity and coherence, the trajectory of scientific life as a chain that entangles a life history with Music Education.

Keywords: Music Education. Trajectory of scientific-life. Biogram.

\section{RESUMEN}

\section{EL BIOGRAMA COMO MARCO TEÓRICO- METODOLÓGICO PARA LA CONSTRUCCIÓN DE LA TRAYECTORIA DE VIDA-CIENTIFICA EN LA EDUCACIÓN MUSICAL}

Este texto es una síntesis de una investigación de maestría completa cuyo tema se centró en la trayectoria de la vida-científica de los investigadores en el campo de la educación musical. Los supuestos teóricos se basaron en conceptos de trayectoria de vida. La metodología utilizada fue de naturaleza cualitativa, basada en la investigación documental cuya fuente estaba en el Currículo Lattes utilizado para completar el Biograma. El objetivo de este texto es presentar cómo se utilizó el Biograma como marco teórico y metodológico. Los datos presentados aquí son extractos de ese enfoque. La trayectoria de la vida-científica es el recorte de toda una vida que hace referencia a la actuación en el campo de la educación musical. Los resultados revelan que el Biograma es un tipo de herramienta metodológica. Es teórico porque lleva el concepto de Biograma al campo de la educación musical y metodológico porque es el instrumento utilizado para la construcción de trayectorias de vida-científica. Es una forma de dar vida al Curriculo Lattes y visibilidad a las trayectorias de vida-científicas a través de la valoración, el resultado de la interpretación. Se concluye que al analizar los registros en el Biograma 
fue posible representar, por su unidad y coherencia, la trayectoria de vida-científica como un encadenamiento que entrelaza una historia de vida con la Educación Musical.

Palabras clave: Educación musical. Trayectoria de la vida-científica. Biograma.

\section{Introdução}

Este artigo é um recorte de uma pesquisa concluída de mestrado em que o objeto de estudo consistiu nas trajetórias de vida-científica de destacados pesquisadores da Educação Musical. Ao delinear esse objeto de estudo, a questão da pesquisa problematizada foi: como as trajetórias de vida-científica de pesquisadores com Bolsa de Produtividade em Pesquisa (PQ) do Conselho Nacional de Desenvolvimento Científico e Tecnológico (CNPq) da Educação Musical vêm se configurando com essa área de conhecimento?

O presente artigo está atrelado ao projeto guarda-chuva denominado "Educação Musical e Pesquisa (Auto)Biográfica: desafios epistemológicos" (ABREU, 2016), que consistiu em acolher estudos e pesquisas em Educação Musical que potencializam dimensões epistemológicas e que abarcam experiências de profissionais em suas interações com conhecimentos que emergem de fatos biográficos filtrados pelo social, cultural e educacional de sujeitos na sociedade contemporânea. Esse projeto se desenvolveu no âmbito do Grupo de Pesquisa Educação Musical e Autobiografia (GEMAB)', operando na vertente de histórias de vida de educadores musicais brasileiros.

A Educação Musical, como campo investigativo, começa no Brasil com a Associação Brasileira de Educação Musical (ABEM) em 1991, com o propósito de consolidar a área (OLIVEIRA, 2012). Portanto, a área não é nova, tem "história, associações, instituições de en-

1 Ver: http://musicobiografia.unb.br/. sino superior, pesquisas, ações formativas [e] proposições frente à Lei no 11.769/08" (SOUZA et al., 2010, p. 87, grifo nosso). As palavras em destaque enfatizam, ou revelam um campo investigativo preocupado desde o princípio com as experiências de seus pesquisadores com a prática de pesquisa. E, como destaca Del-Ben (2017), isso vem acontecendo desde a formação dos sete primeiros doutores da Educação Musical que, ao se formarem na área, abriram caminhos para a Educação Musical como campo investigativo (Cf. LEITE-OLIVEIRA, 2019, p. 28).

0 foco deste texto é apresentar um novo formato de biograma e sua utilização na pesquisa como referencial teórico-metodológico para se chegar nas trajetórias de vida-científica de pesquisadores da Educação Musical no Brasil.

Os caminhos metodológicos da pesquisa consistem numa abordagem qualitativa em fontes documentais - nesse caso, o Currículo Lattes de pesquisadores com Bolsa de PQ, resultante da pesquisa documental. O biograma inicialmente apresentou-se como um dispositivo para a técnica de pesquisa. Entretanto, com os avanços da pesquisa, tornou-se o referencial teórico-metodológico e foi usado para análise dos dados fundamentando-se na valoração construída pela hermenêutica.

Os biogramas preenchidos a partir dos Currículos Lattes com base em cinco critérios do CNPq constituem a trajetória de vida-científica dos cinco pesquisadores PQ's da Educação Musical. A partir da teoria da hermenêutica, 
observando o paradigma interpretativo da valoração, e fazendo o cruzamento dos dados dos biogramas, identifiquei as características gerais dos pesquisadores. Esse processo ajudou a chegar às primeiras compreensões das trajetórias de vida-científica dos pesquisadores. Com isso, foi possivel identificar características específicas das trajetórias. Os resultados mostraram o termo nocional de biograma e de trajetória de vida-científica para a Educação Musical e inferências sobre um projeto coletivo de área que norteou esta pesquisa.

Os caminhos trilhados na pesquisa, bem como seus resultados, só foram possiveis através da utilização do biograma. Nesse ponto, retomo esse aspecto, pois foi a partir de balanços da produção de conhecimento gerado na área que encontramos pesquisas de autores que abordam, dentre outros assuntos, identificação de perspectivas teórico-metodológicas (SOUZA, 1996); diversidade temática, teórica e metodológicas (BELLOCHIO, 2003; DEL-BEN, 2003; SANTOS, 2003); e metodologias específicas de pesquisa (FIGUEIREDO; SOARES, 2010, 2012; FIGUEIREDO; SOARES; SCHAMBECK, 2015).

Ocorre que para atingir os propósitos da pesquisa empreendida no mestrado, tais metodologias abordadas pelos autores supracitados não atendiam aos propósitos do estudo. Era preciso uma abordagem metodológica que valorasse os registros daqueles sujeitos que se construíram com a área da Educação Musical.

Os caminhos tomados para a construção das trajetórias de vida-científica levaram-me a entender que tal processo precisou trilhar novos caminhos metodológicos para obtenção dos resultados esperados. Encontrei em Bondía (2002, p. 24) um olhar para as experiências cuja trajetória de vida inscreve algumas marcas, deixando vestígios e alguns efeitos. Isso se inscreve nas escritas de si que podem ser descritas de diferentes maneiras, como é o caso do Currículo Lattes.
Ao considerar que o Currículo Lattes, fonte documental desta pesquisa, é "quase um relato (auto)biográfico" (NASCIMENTO; NUNES, 2014, p. 1079) e que as trajetórias de vida-científica são os próprios biogramas, entendo que tal caminho funde a biografia com o biograma evidenciando trajetórias de vida-científica. A trajetória de vida-científica traçada por meio do biograma é um tipo de instrumentalizar metodologicamente para um novo modo de se fazer pesquisa.

A partir dessas reflexões e das ideias de Abreu (2018), bem como dos construtos de Bolívar, Domingos e Fernández (2001), unifiquei tal diversidade de pensamentos na unicidade do conceito de biograma e trajetórias de vida-científica. O "biograma" - termo de origem grega usado em palavras que tenham relação com o ser vivo $[$ bio $=$ vida + grama $=$ linha $/$ trajetória] - é onde a história da vida de alguém é narrada. É, portanto, um dispositivo de escrita que auxilia, a partir de contínua reflexão, a dar unidade e, de certa maneira, coerência às circunstâncias que foram formadoras na elaboração das trajetórias de vida-científicas dos pesquisadores. A trajetória de vida-científica é a fase científica em que o pesquisador se encontra, cujo capital/produto parte das epistemologias que se (inter)relacionam e ajudam diretamente na construção e consolidação de uma área de conhecimento.

A trajetória de vida-científica é o recorte de uma vida inteira que faz referência à atuação no campo da Educação Musical. De forma que o biograma é a própria trajetória de vidacientífica.

\section{Caminhos teórico-metodológico da pesquisa}

Descrevo neste tópico os caminhos lógicos da investigação. A abordagem teórica utilizada neste trabalho é a qualitativa, que se justifica 
devido à técnica de coleta, análise e interpretação dos dados. Apesar desta pesquisa conter aspectos estatísticos ou dedutivos (quantitativo) e os dados estarem organizados em quadros, tabelas e gráficos, necessitamos deles para a escrita de textos narrativos e descritivos (PRODANOV; FREITAS, 2013, p. 71, 92, 114). Esses textos são subjetivos ou indutivos e são necessários para se chegar à valoração.

O procedimento técnico escolhido é a pesquisa documental. É uma pesquisa ampla. Os materiais usados na pesquisa documental, por geralmente serem fontes mais recentes e não terem sido analisados, podem ser reelaborados conforme o andamento da pesquisa. Justifico a seguir, o uso da pesquisa documental.

0 presente estudo tem nas fontes documentais, como escolha metodológica, o material resultante da pesquisa documental. A análise documental, a partir das fontes documentais, constitui-se de uma técnica importante, pois revela novos olhares e soluções possiveis sobre determinada temática (LUDKE; ANDRÉ, 1986; BOGDAN; BIKLEN, 1994). A presente pesquisa tomou como amostra cinco Currículos Lattes dos pesquisadores da Educação Musical com Bolsa PQ do CNPq. A trajetória de vida-científica pode ser captada por entrevista (história oral), relato circunstanciado autobiográfico (depoimentos pessoais), mas, neste estudo, usaremos os dados ${ }^{2}$ registrados no conteúdo dos Currículos Lattes, pois entendemos que as trajetórias de vida-científica partem da escrita de si nessa fonte documental.

A vida é mais que um Currículo Lattes, mas nele os registros esquemáticos se dispõem a materializar aquilo que constitui a vida de um profissional. O Currículo Lattes é um registro de padrão nacional (CNPq, 2018) e pode ser utilizado para a caracterização de redes de colaboração científica para a Educação Musical.

2 Também usaremos os dados dos Diretório de Grupos de Pesquisa, e os Indicadores da Produção informados pelo CNPq por intermédio da Plataforma Lattes.
Quando o pesquisador faz tal registro, subjetivamente, deixa exposta sua identidade, ou seja, sua trajetória de vida-científica.

Cabe aqui esclarecer que a expressão (auto)biográfico trata do método, e autobiografia trata do gênero literário. Esta pesquisa se constitui como estudos da Educação Musical e pesquisa (auto)biográfica.

Entendemos, com base em todos os estudos supramencionados, que o Currículo Lattes é bio, é vida, é texto, é fala, é jornada, é autobiografia. Nele, é forjada uma identidade - um documento, um documento de identidade. Nele, está a base fundante para a trajetória de vida-científica de pesquisadores de uma determinada área, como é o caso da Educação Musical.

Com a trajetória de vida-científica capturada por intermédio de fontes documentais pelos biogramas, foi possivel ver nos fatos aquilo que denomina-se evolução de vida-científica do pesquisador. Com a escrita de si nos Currículos Lattes vistos como dados por uma outra perspectiva, foi possivel perceber convenções. Dessa forma, busquei situar essas convenções dentro de um discurso que atendesse aos pressupostos desta pesquisa. Esta escrita baseia-se em contextos acadêmicos, sociais, econômicos, situacionais e culturais. Também é uma escrita específica que fornece relatos de uma vida comprometida com sua área de conhecimento.

Ao ler os Currículos Lattes dos cinco pesquisadores, não foi possivel enxergar claramente como ajudaram a construir e consolidar a área de conhecimento. Isso só é possivel pelo biograma que é preenchido por critérios do CNPq e que atendem às demandas científicas no país. Com isso, foi possivel refletir sobre o contexto e interpretar os parâmetros subjetivos do Currículo Lattes. Só dessa forma foi possivel perceber as possiveis entrelinhas dessa fonte documental e, com isso, catego- 
rias para a construção dos biogramas, aumentando assim nossa compreensão dessa fonte documental.

\section{Biograma como referencial teórico-metodológico}

O biograma tem origem nos estudos de Agra e
Matos (1997) e foi criado para estudar trajetória de vida. Na perspectiva de Bolivar, Domingo e Fernández (2001), por meio do biograma que observa os fatos cronológicos, os acontecimentos e avaliação, é possível elaborar um mapa das trajetórias do indivíduo. Segue abaixo um exemplo do quadro apresentado pelos autores supracitados.

Quadro 1- Biograma de trajetória profissional

\begin{tabular}{|c|c|c|}
\hline Fatos Cronológicos & Acontecimentos & Avaliação \\
\hline $1961-1965 ?$ & Escola Normal de Granada & - Carreira curta \\
Magistério & & - Treinamento escasso \\
\hline
\end{tabular}

Fonte: Bolívar, Domingo, e Fernández (2001, p. 179).

A coluna do centro trata resumidamente dos acontecimentos mais importantes. A coluna da esquerda apresenta a data. Por fim, na coluna da direita, encontra-se a avaliação, na qual são feitas as anotações resumidas de significado que o pesquisador dá a cada aconte- cimento.

Para elaborar a trajetória de vida-cientifica, um novo formato de biograma foi desenvolvido (ver Quadro 2) com os critérios do CNPq - como títulos - e o acréscimo do termo valoração.

Quadro 2 - Biograma de trajetória de vida-científica

\begin{tabular}{|c|c|c|}
\hline \multicolumn{3}{|c|}{ Critérios do CNPq* } \\
\hline CRONOLOGIA & ACONTECIMENTOS & VALORAÇÃO \\
\hline $2010-2019$ & Orientação de doutorado & \multirow{5}{*}{ RAPIH } \\
\hline $2002-2018$ & Parecerista de periódico científico & \\
\hline $1996-2018$ & Artigos publicados em periódicos & \\
\hline 2001 & Livro & \\
\hline $2003-2011$ & Assessoria e consultoria & \\
\hline
\end{tabular}

Fonte: elaborado pelo autor com base em Abreu (2018); Bolívar, Domingos e Fernández (2001).

Nota: Resultado da Análise do Paradigma Interpretativo da Hermenêutica (RAPIH).

* Critérios do CNPq: a) produção científica; b) formação de recursos humanos em nível de pós-graduação; c) contribuição científica e tecnológica e para inovação; d) coordenação ou participação principal em projetos de pesquisa; e) participação em atividades editoriais e de gestão científica e administração de instituições e núcleos de excelência científica e tecnológica.

O diferencial do biograma desenvolvido para esta pesquisa está na valoração. A valoração é resultado da análise do paradigma interpretativo da hermenêutica. Ao analisar, por esses registros no biograma, esses acontecimentos e cronologia das trajetórias dos sujeitos com intuito de extrair a valoração dos acontecimentos, foi possivel representar a trajetória de vida-científica como um encadeamento que enreda uma história de vida com a Educação Musical.

Num primeiro momento, o biograma é um dispositivo de escrita, em que a história da vida é narrada, que auxilia, a partir de contí- 
nua reflexão, a dar unidade e, de certa maneira, coerência às circunstâncias que foram formadoras na elaboração de/das trajetórias de vida-científicas de/dos pesquisadores. A trajetória de vida-científica é o recorte de uma vida inteira que faz referência à atuação no campo da Educação Musical.

Por ser um tipo de instrumentalizar metodologicamente para um novo modo de se fazer pesquisa na área, o biograma é o referencial teórico-metodológico. Teórico por trazer o conceito para o campo da Educação Musical, e metodológico por ser o instrumento usado para a construção das trajetórias de vida-científica. Ele é um mapa representativo das trajetórias de vida-científica de pesquisadores. Nesse instrumento, os acontecimentos e a cronologia dos fatos mais importantes relacionados à produção científica, tecnológica e de inovação são descritos. É um modo de dar vida ao Currículo Lattes e visibilidade às trajetórias de vida-científicas pela valoração.

Esse referencial teórico-metodológico visa trazer contribuições e inovação no campo da metodologia científica, pois nos leva a refletir os caminhos percorridos por pesquisadores ao longo da vida-científica e seus significados para si e para a área de conhecimento. Nisso reside a importância deste artigo: mostrar um novo formato de biograma construído com critérios do CNPq, cuja valoração dos acontecimentos é resultante da teoria da hermenêutica.

\section{Biograma - fonte e instrumento para a construção de trajetória de vida-científica}

Proponho o uso do biograma - adaptando-o às nossas necessidades - considerado um estudo longitudinal retrospectivo, uma vez que os dados coletados são para traçar a trajetória de vida-científica de pesquisadores, nesse caso, do CNPq da Educação Musical.
A biografia, heterobiografia e autobiografia são graficamente traduzidas no biograma. Biografia "é a vida de um único sujeito, entendida no seu tempo e percurso histórico"; heterobiografia diz respeito a "fatos significativos na vida dos sujeitos, recolhidos e registrados por outros, numa multiplicidade de fontes documentais"; autobiografia, gênero literário, é onde a "história de vida de alguém é escrita ou narrada pela pessoa biografada" (MANITA, 2001, p. 39, 40).

É por meio do biograma que foi possivel enxergar os itinerários de vida-científica no Currículo Lattes dos cinco pesquisadores da Educação Musical. Sem esse instrumental-metodológico não seria possível chegar à resposta da questão-problema da pesquisa.

\section{A construção e preenchimento do biograma}

Primeira parte - delineamento. Para a construção do biograma de trajetória de vida-científica, foi preciso empreender várias leituras sobre a fonte de pesquisa - o Currículo Lattes. Portanto, levantar dessa fonte a trajetória percorrida do que fizeram os pesquisadores mostra um jeito de enxergar uma área de conhecimento. Os biogramas foram elaborados na ordem crescente conforme os níveis do CNPq (Cf. LEITE-OLIVEIRA, 2019, p. 80).

Algumas fontes, para a construção dos biogramas, foram extraídas das ideias de autores de fora da área como é o caso de Bolívar, Domingo e Fernández (2001). De dentro da área da Educação Musical, trago as ideias de Abreu (2019) que contribuíram no adensamento desses biogramas, bem como para as fases da análise.

Após vários exercícios estruturantes do biograma, como títulos deste, optei por colocar cinco critérios do $\mathrm{CNPq}^{3}$, órgão que observa

$3 \mathrm{CNPq}$ - principal órgão que fomenta a pesquisa no 
por meio de seus critérios quem está de acordo com ele. Assim, iniciei o processo de preenchimento dos biogramas observando paralelamente os critérios com a cronologia dos fatos e os acontecimentos. Observando cada critério separadamente, busquei respostas no Currículo Lattes. Os critérios do CNPq estudados para ajudar a sistematizar os biogramas dos cinco pesquisadores foram retirados da Chamada CNPq no 06/2019 - Bolsas de PQ e outros documentos (CNPq, 2018; 2017; 2015; 2014). Essa imersão ajudou na percepção de categorias e subcategorias.

Segunda parte - preenchimento. Os biogramas foram preenchidos a partir dos Currículos Lattes, e, sempre que necessário, as informações contidas nos Currículos Lattes foram confrontadas com os indicadores da produção, ambos da Plataforma Lattes.

Terceira parte - primeiros resultados. Ao observar todos os biogramas delineados após o processo de construção, entendo, como primeiros resultados desta pesquisa, que eles são as próprias trajetórias de vida-científica dos cinco pesquisadores. Essas trajetórias nasceram por esses biogramas construídos com base em cinco categorias do CNPq - que são as mesmas categorias, direta ou indiretamente, para todos as áreas do conhecimento.

Pelos biogramas, os objetivos propostos foram respondidos. 0 passo seguinte consistiu em extrair, num paradigma interpretativo da hermenêutica, a valoração dos acontecimentos dessas trajetórias com intuito de verificar características de um panorama de área.

\section{Análise dos dados e seus processos}

Para analisar os dados, também tomei por

país: https://cartacampinas.com.br/2019/04/principal-orgao-que-financia-a-pesquisa-no-brasil-o-cnpq -esta-inviabilizado-por-falta-de-recursos/. base os construtos de Bolivar, Domingo e Fernández (2001) para tratar da teoria da hermenêutica para se chegar ao paradigma interpretativo da valoração. Na valoração, usouse como técnica de investigação a análise de conteúdo/textos.

\section{O termo "valoração" na perspectiva da hermenêutica}

A valoração são os apontamentos de sentido que o pesquisador dá a cada feito/acontecimento memorável do indivíduo/grupo. Com os acontecimentos registrados, é no momento da valoração que estes ganham significados. Nesse sentido, os significados atribuídos são para aqueles acontecimentos que estruturam uma trajetória de vida, nesse caso, científica. A valoração está naquilo que estrutura, que constrói, que cria mecanismos para uma trajetória de vida ser uma vida-científica. A valoração nesta pesquisa ocorreu pela interpretação dos biogramas pelo pesquisador/autor através da teoria da hermenêutica ao tomar como fundamentos estruturantes os conteúdos/textos dos biogramas, valorando a importância das trajetórias de vida-científica para a Educação Musical. 0 âmbito da hermenêutica se estende à interpretação de todos os tipos de texto (VELOSO, 2002).

A hermenêutica, segundo Bolivar, Domingo e Fernández (2001, p. 186), "permite dar sentido e compreender aspectos cognitivos, afetivos e de ação" dos pesquisadores, entendidas aqui como trajetórias de vida-científica de pesquisadores $P Q$ s. Entendo, portanto, que a hermenêutica proporciona sentido por dar a compreender as trajetórias de vida-científica pelos acontecimentos vividos. Nesses acontecimentos, estão inseridas as manifestações subjetivas do indivíduo que ajudam a enxergar características da Educação Musical como área. 


\section{Processos de análise}

A fase de análise e interpretação dos dados se desenvolveu a partir das evidências observadas durante e após o preenchimento do biograma. Com os dados retirados dos Currículos Lattes e dos indicadores da produção, os biogramas dos pesquisadores foram montados. Os biogramas delineados já se configuram como as trajetórias de vida-científica dos cinco pesquisadores.

Fundamentando-se na teoria da hermenêutica (GIL, 2008, p. 18-24) para interpretação de todos os tipos de texto (VELOSO, 2002) e também com base interpretativa nos estudos de Bolivar, Domingo e Fernández (2001), busquei mostrar aspectos gerais interpretando os biogramas para geração de dados dispostos em gráficos e figuras já com um olhar instrumentalizado para as trajetórias de vida-científica dos cinco pesquisadores. Assim, ao olhar para as trajetórias de vida-científica, percebi como cada pesquisador vem se comportando, no sentido de ações tomadas. Pude, a partir das nuances individuais, mostrar como os cinco pesquisadores conversam entre si.

$E$, finalmente, a interpretação de toda a pesquisa. Fase elaborada com base na teoria da hermenêutica em que é mostrado o posicionamento do próprio autor pelo aspecto valorativo considerado de maior significado das trajetórias de vida-científica dos pesquisadores $P Q s$.

A seguir, apresento alguns dados desse processo de análise com a metodologia proposta. Reitero que o referencial teórico-metodológico é foco deste artigo.

\section{Alguns excertos dos dados}

Diálogos foram estabelecidos entre autores que fazem fronteira com a Educação Musical bem como da própria área, a fim de trazer com- preensões de como vêm se configurando as trajetórias de vida-científica dos cinco pesquisadores com Bolsa de PQ da Educação Musical. Esses diálogos pautaram-se sobre a temática deste estudo e nos cinco critérios do CNPq para ver como os cinco pesquisadores abordam, ou se comportam frente a tais assuntos.

Para estabelecer um diálogo entre os cinco pesquisadores e demais autores, elaborei um gráfico para cada critério para mostrar aproximações dessas cinco trajetórias para, talvez, mostrar um propósito de área. Nos gráficos, expus o quantitativo dos critérios e neles, suas subcategorias (convenções) secundárias, ternárias e quaternárias. 0 critério 1, por exemplo, trata da produção científica. Nele, temos a produção bibliográfica (subcategoria secundária), orientações concluídas (subcategoria ternária), orientações concluídas em mestrado (subcategoria quaternária).

O passo seguinte foi ver como cada categoria e subcategoria têm sido usadas para alimentar a Educação Musical ou, posto de outro modo, como cada categoria e subcategoria vêm configurando essa área de conhecimento. Nesse ponto, busquei estudos que abordassem as temáticas das categorias e subcategorias de fora da área e depois da própria área. Essas aproximações visaram mostrar os caminhos fundantes da área.

Procurei, na pesquisa empreendida, "estabelecer as relações necessárias entre os dados obtidos" e as "hipóteses formuladas", buscando "ultrapassar a mera descrição dos resultados obtidos, acrescentando algo novo ao que já conhecemos sobre o assunto" (PRODANOV; FREITAS, 2013, p. 115), nesse caso, trajetória de vida-científica de pesquisadores.

Os cinco pesquisadores estudados nesta pesquisa possuem diferentes formações em nível de pós-graduação stricto sensu. Liane Hentschke e Jusamara Vieira Souza possuem doutorado em Educação Musical, Luciana Marta 
Del-Ben em Música, Luís Ricardo Silva Queiroz têm formação em Música cuja área de concentração é em Etnomusicologia. E, por fim, Cláudia Ribeiro Bellochio com doutorado em Educação.

Sob diferentes visões epistemológicas, esses pesquisadores têm se orientado dentro da área com olhares distintos, mas com uma preocupação coletiva que é a construção de uma área, seja pelo viés da formação de professores, como é o caso de Liane Hentschke e Cláudia Ribeiro Bellochio; pela Educação Musical Escolar da qual trata Luciana Marta Del-Ben; ou da Educação Musical e Cotidiano com uma abordagem da sociologia da Educação Musical como vem se debruçando Jusamara Vieira Souza; e, por fim, Luís Ricardo Silva Queiroz que tem buscado dialogar na perspectiva da Educação Musical como Cultura.
Quantitativamente os cinco gráficos a seguir mostram como essas trajetórias de vidacientífica dos cinco pesquisadores conversam entre si, mostrando nuances individuais e coletivas. Com isso, é possivel observar como vêm se constituindo.

\section{Os pesquisadores e a produção científica}

De acordo com Witter (1997, p. 09), “produção científica é a forma pela qual a universidade ou instituição de pesquisa se faz presente no saber-fazer-poder ciência [e entre outras coisas é também]; a forma de se fazer presente não só hoje, mas também amanhã". A seguir, apresento o gráfico referente à produção científica dos pesquisadores:

Gráfico 1 - Produção científica dos cinco pesquisadores PQ

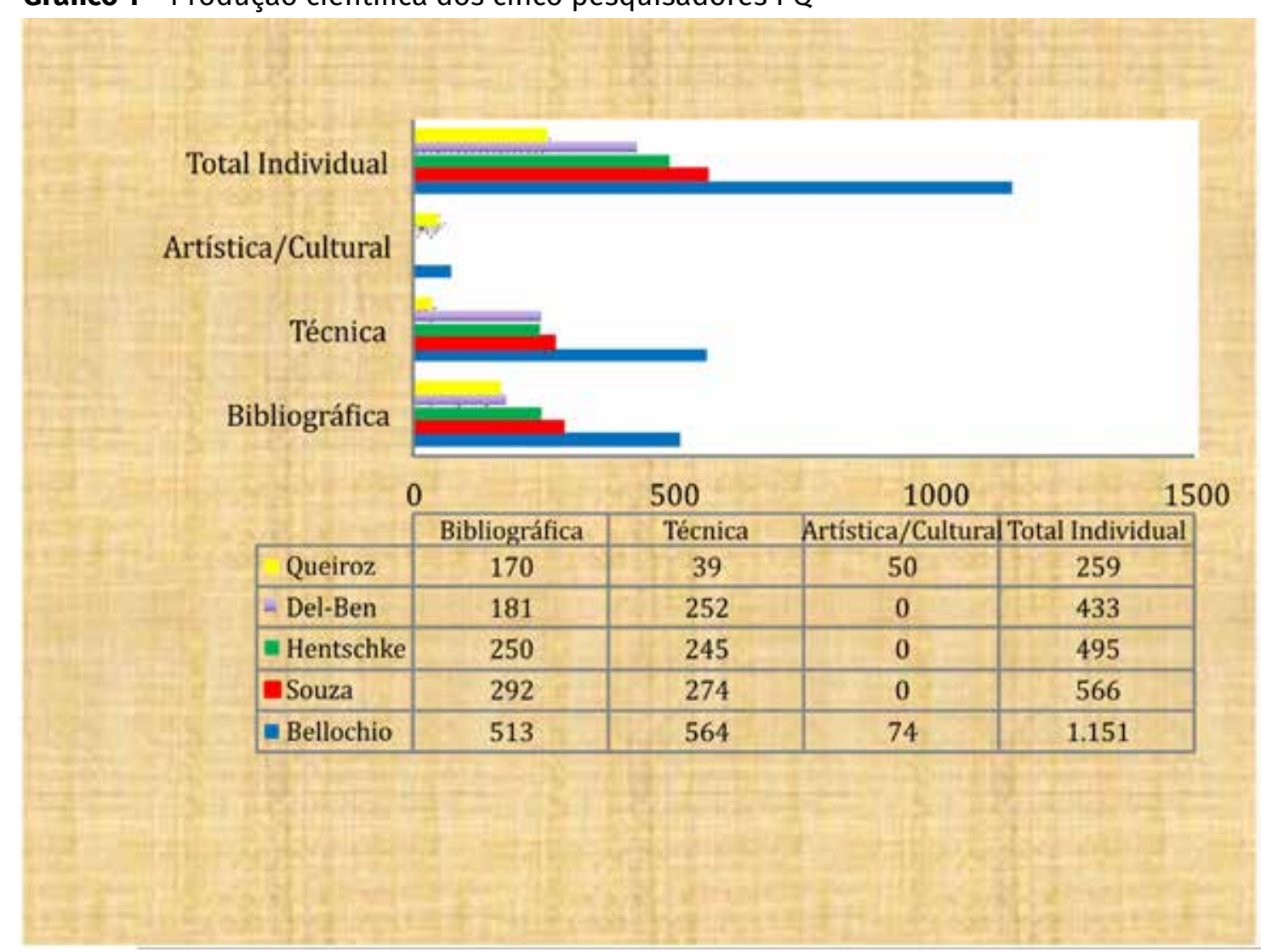

Fonte: elaborado pelo autor.

Esses cinco pesquisadores, ao longo de suas trajetórias, mantiveram uma produção constante, com destaque para a produção bibliográfica, totalizando 1.392 (orientações, trabalhos publicados em anais de eventos, artigos publicados em periódicos, resumos, livros e capítulo de 
livros), e a produção técnica com 1.374 trabalhos (apresentações de trabalhos, assessoria e consultoria, cursos de formação, reuniões, projetos, auditoria). A produção cultural apresenta-se com menor quantidade, 124 , somente nos indicadores da produção de dois dos cinco pesquisadores. Essa produção tem alimentado tantos os cursos de graduação como os de pósgraduação no país, nos mais vários aspectos.
Formação de recursos humanos dos cinco pesquisadores em nível de pós-graduação

A área da Educação Musical no país vem crescendo de modo significativo e isso vem ocorrendo, conforme a pesquisa empreendida, pela "expansão e consolidação da Pós-Graduação" (DEL-BEN, 2010, p. 26, grifo nosso).

Gráfico 2 - Formação de recursos humanos dos cinco pesquisadores em nível de pós-graduação

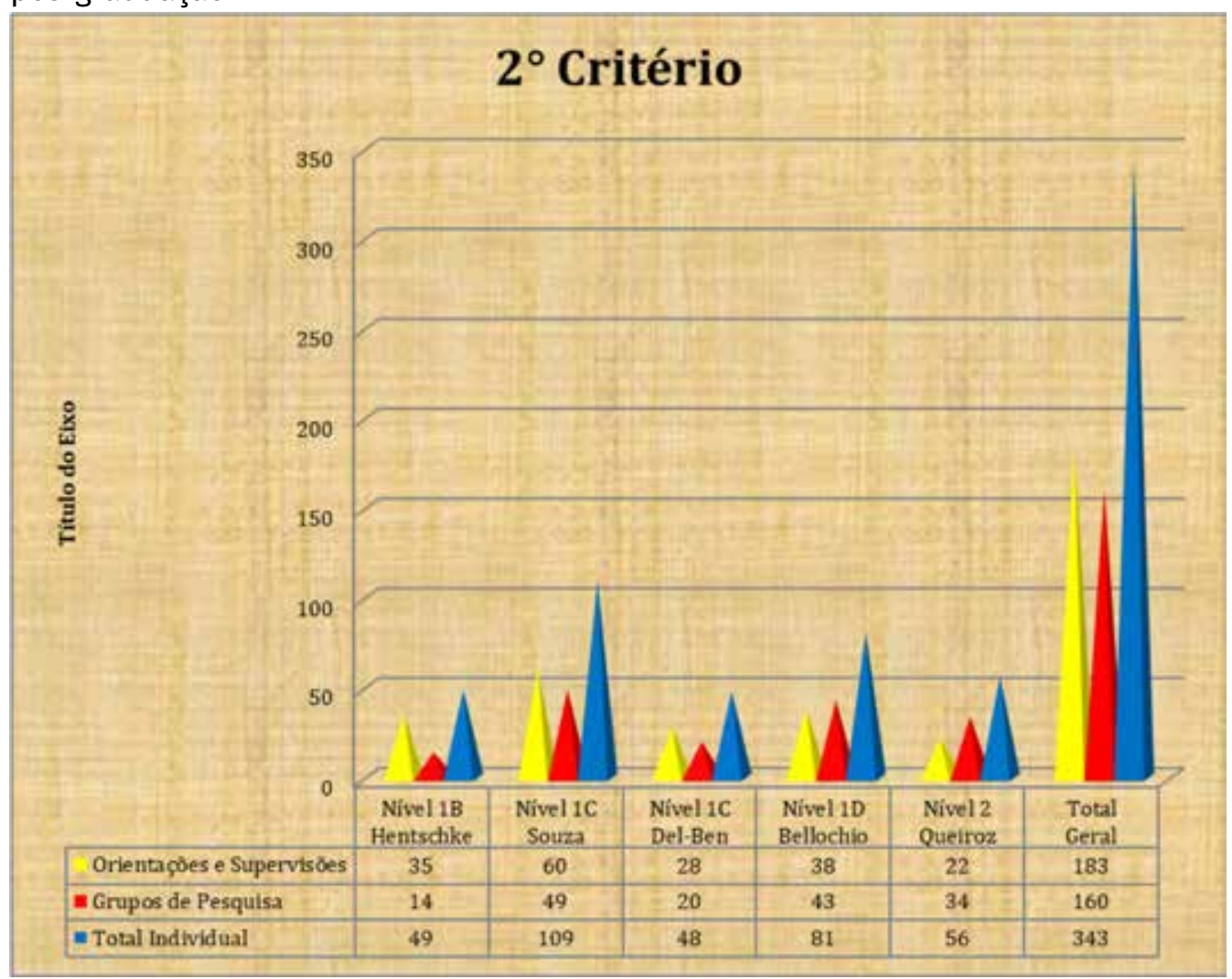

Fonte: elaborado pelo autor.

Os pesquisadores deste estudo atuam em universidades, desde o ano de 1995 até os dias atuais (uma exceção), na formação de recursos humanos, retroalimentando a área. O panorama atual, janeiro de 2020 da pós-graduação, a partir da última Avaliação Quadrienal ${ }^{4}$ (20172020) contabiliza 29 programas/cursos stricto sensu em Música (18 mestrados e 11 doutorados). Cabe esclarecer que Cláudia Ribeiro Bel-

4 Ver: https://sucupira.capes.gov.br/sucupira/public/ index.jsf\#. lochio não é vinculada ao Programa de PósGraduação (PPG) de Música. A pesquisadora $P Q$ atua no ensino, pesquisa e extensão na Universidade Federal de Santa Maria (UFSM), Centro de Educação, Departamento de Metodologia do Ensino (Linha de Pesquisa Educação e Artes).

Apresento, a seguir, os PPGs de cunho acadêmico no Brasil na atualidade por estado e instituição. 
Figura 1 - PPG em Música e Artes/Música por estado e instituição

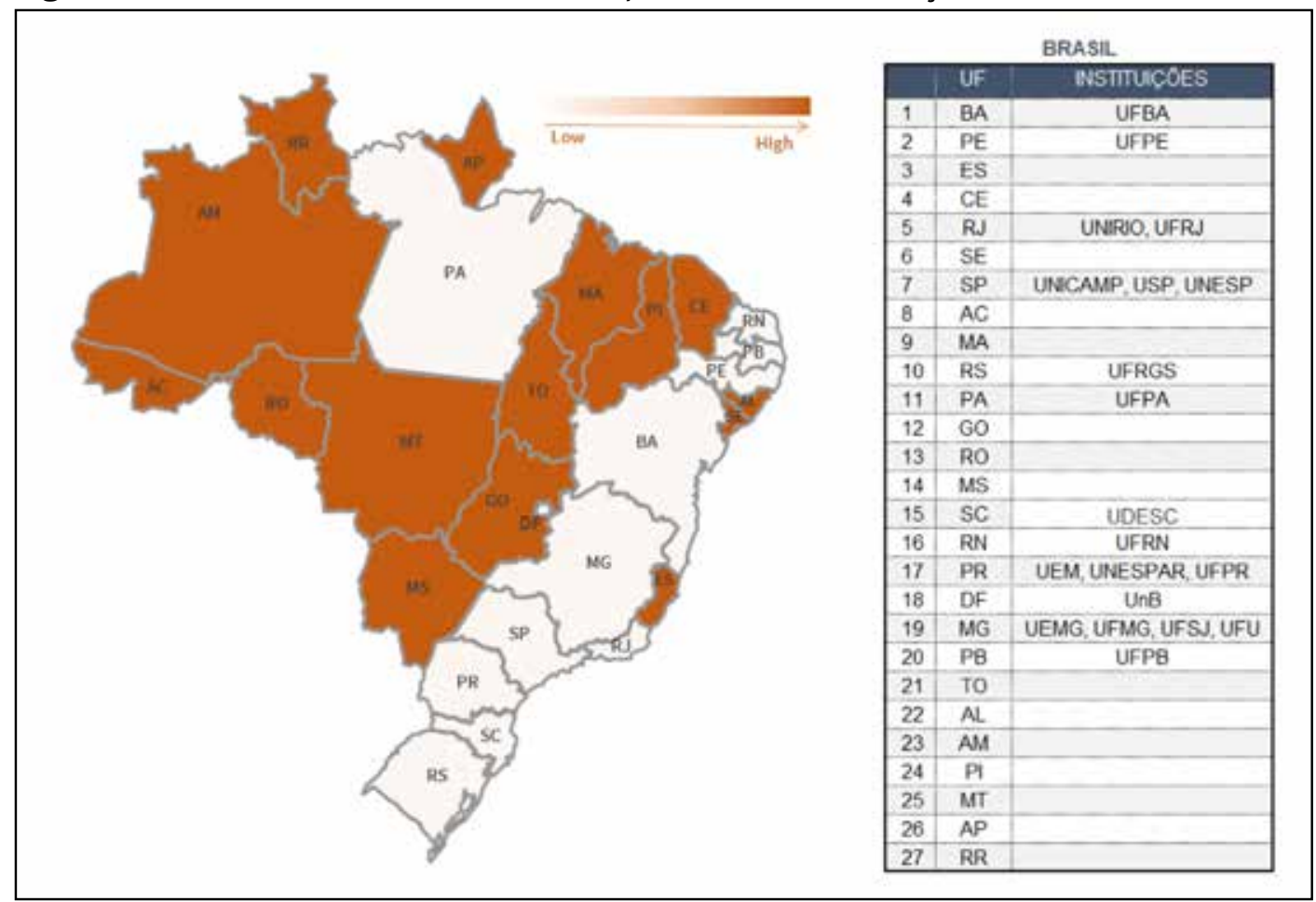

Fonte: elaborada pelo autor com base nos dados da Plataforma Sucupira.

Esses PPGs em Música, incluindo Artes/Música, estão presentes em 12 estados, partes claras, das 27 unidades federativas. Na pós-graduação, formam-se profissionais qualificados para os mais diversos ambientes de trabalho e para o avanço de conhecimento gerado por meio de pesquisas nas mais diversas áreas.

\section{Contribuição científica e tecnológica e para inovação}

Esse critério traz diálogos dentro do próprio campo investigativo da Educação Musical e de outros campos do saber que fazem fronteira com a área.

Nesse sentido, por tratar da contribuição científica, tecnológica e para a inovação, os olhares desses pesquisadores de dentro da Educação se ampliam trazendo contribuições para a Educação Musical.

A produção representa a contribuição do pesquisador para uma área. A contribuição científica de um pesquisador é medida pelo conjunto e a qualidade da sua obra, ou seja, "quanto mais impacto cause uma publicação científica maior é a sua qualidade como contribuição científica" (DROESCHER; SILVA, 2014, p. 180). É, portanto, por intermédio dos artigos científicos publicados em periódicos que vemos o reflexo da produção científica da Educação Musical. Os periódicos nos quais os pesquisadores publicam/publicaram são: $R e$ vista da ABEM e Anais, Revista Opus, Revista Música Hodie, PerMusi, Revista Em Pauta, Série Estudos, Debates, e outras (nacionais); Animus, Bioacoustics, Circuit, Consciousness, Literature and the Art Critical Musicology, Cromohs, Ctheory, Cultronix, De música, Differences, Discourses in Music, Echo, EJournal, Enculturation, Ethnomusicology OnLine, Eunomios, e outros (internacionais).

Contribuição tecnológica e inovação. De acordo com a chamada PQ 2018 - COCHS_AC - Artes (Vigência 2018 a 2020) - a contribuição tecnológica e inovação não são critérios para Artes. Não havendo, portanto, referência alguma para essa grande área, entende-se que não há exigência quanto a esse critério. 
Gráfico 3 - Contribuição científica e tecnológica e para inovação

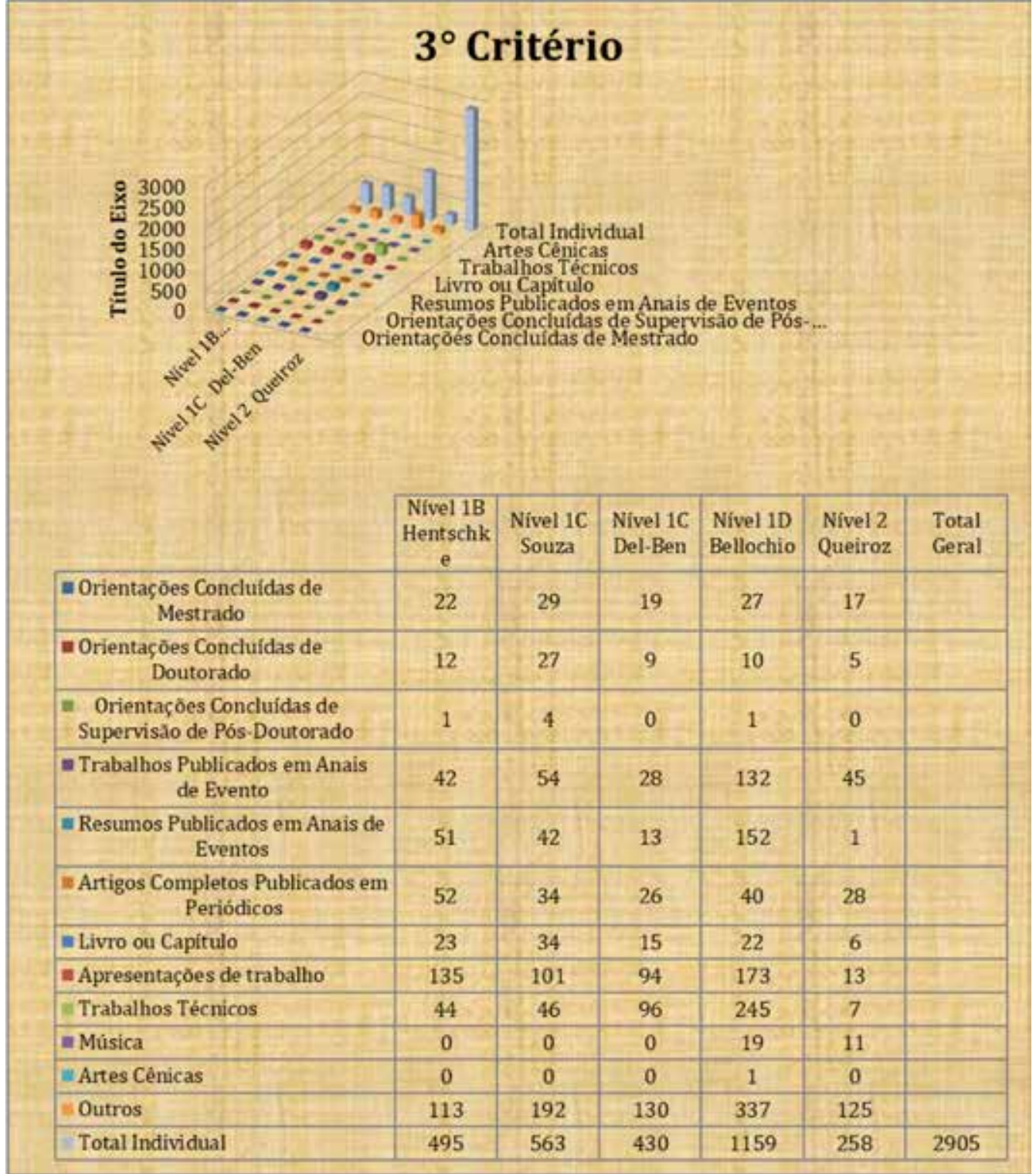

Fonte: elaborado pelo autor.

Dentro da área da Educação Musical no Brasil foram encontradas somente duas autoras que falam sobre contribuição tecnológica e inovação: Souza (2015) e Del-Ben (2014). Nas palavras de Souza (2015. p. 23), "ciência, tecnologia e inovação são termos profundamente integrados e articulados". Segundo a autora, esses termos foram citados inicialmente no ano de 2013, em mesa redonda da ABEM durante o XXI Encontro Anual, apesar de estar diretamente ou indiretamente presente nas pesquisas da área. "A ciência tem como objetivo produzir conhecimentos novos relevantes para a sociedade" (Ibid., p. 24). A tecnologia é um meio para o conhecimento "transposto, codificado" (Ibid., p. 25). A inovação precisa visar "o desenvolvimento humano que promova uma melhor distribuição de renda e inclusão social" (Ibid., p. 39). Para Del-Ben (2014, p. 131), as políticas referentes à ciência, à tecnologia e à inovação (C,T\&I) são "eixos estruturantes do desenvolvimento do país" (DEL-BEN, 2014, p. 131).

A partir dessas leituras, entende-se que no campo pedagógico-musical contribuição tecnológica e inovação podem ser entendidas como um novo achado, mas que dependendo do tempo-espaço-sujeito, é só uma descober- 
ta individual que já foi inventada/imaginada por outro.

\section{Coordenação ou participação principal em projetos de pesquisa}

Os projetos de pesquisa científica nas mais diversas áreas visam contribuir significativamente para o aprofundamento e ampliação dos conhecimentos adquiridos, sobretudo, para o desenvolvimento do país. As instituições de ensino e pesquisa têm por objetivo implantar e/ou ampliar os projetos de pesquisa. São nessas instituições e/ou órgãos governamentais que estão inseridos os pesquisadores $\mathrm{PQs}$ da Educação Musical na coordenação ou participação principal em projetos de pesquisa.

Percebe-se, conforme Gráfico 4, que os projetos seguem um curso ininterrupto o que demonstra um compromisso constante dos pesquisadores na busca por avanços para área. Os estudos que surgem desses projetos concentraram-se nas linhas de pesquisa dos grupos de pesquisa.

Gráfico 4 - Coordenação ou participação principal em projetos de /pesquisa

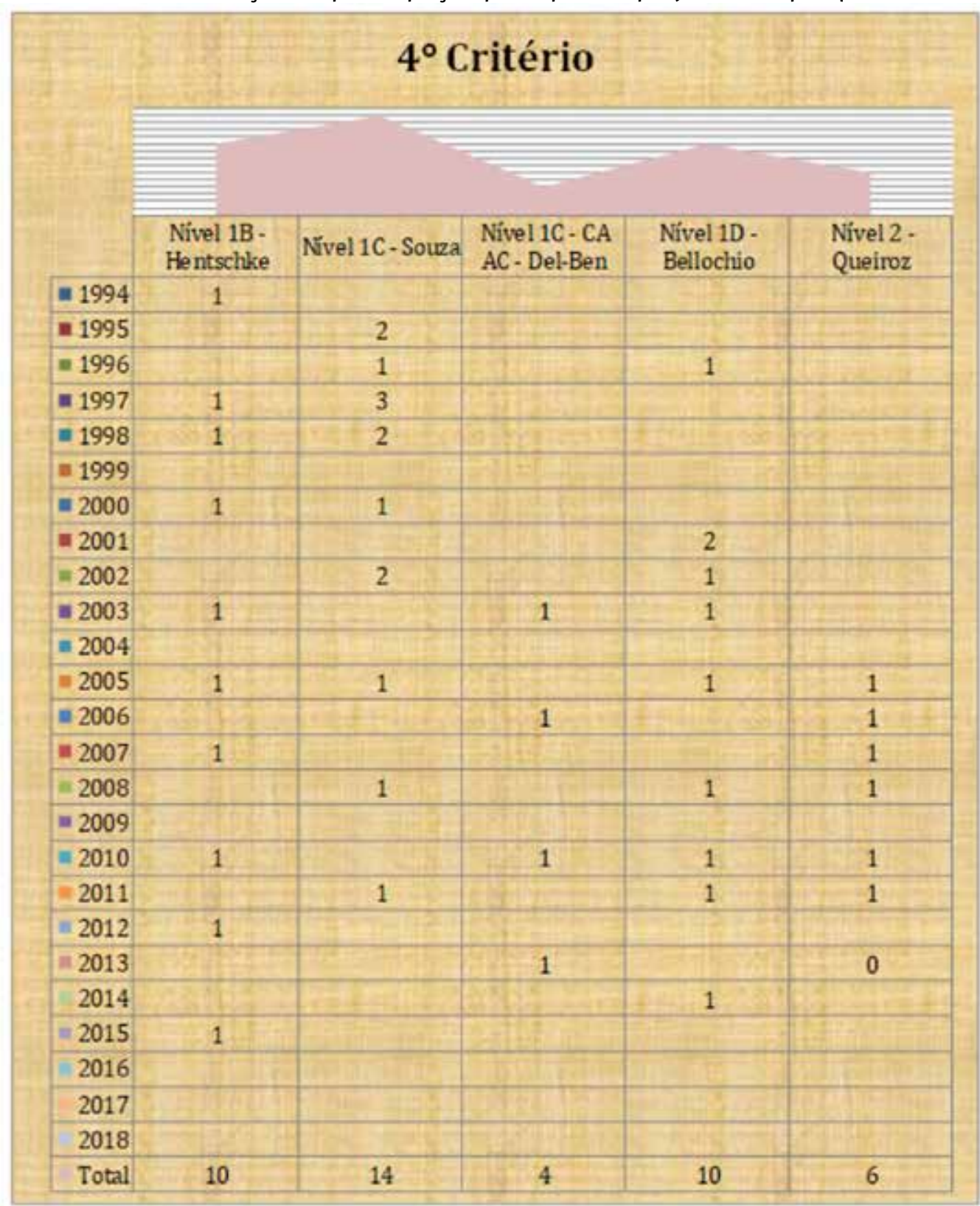

Fonte: elaborado pelo autor. 
Os resultados desses trabalhos são apresentados em congressos nacionais e internacionais, bem como publicados em periódicos nacionais e internacionais de grande representatividade para a Educação Musical.

Foram contabilizados 44 projetos de pesquisa. Neles, verifica-se: o compromisso com e para o desenvolvimento de suas epistemologias; a busca por aprofundamento dos conhecimentos já adquiridos pela área de acordo com suas linhas de pesquisa; a elaboração de materiais didáticos; o aprofundamento e geração de conhecimento; e a formação de recursos humanos. É nessa perspectiva que seguem esses projetos. A pós-graduação, por meio de projetos de pesquisa, é um celeiro para a retroalimentação de qualquer área do conhecimento.

Os pesquisadores e as atividades editoriais e de gestão científica e administração de instituições e núcleos de excelência científica e tecnológica

Essa categoria diferencia-se das demais por sua extensão. As seis subcategorias que emergiram nessa categoria mostram onde os pesquisadores exercem atividades. São elas: atuação profissional, produção técnica, membro de corpo editorial, membro de comitê de assessoramento, revisor de periódico, e revisor de projeto de fomento.

Gráfico $5^{\circ}$ Critério - Participação em atividades editoriais e de gestão científica e administração de instituições e núcleos de excelência científica e tecnológica

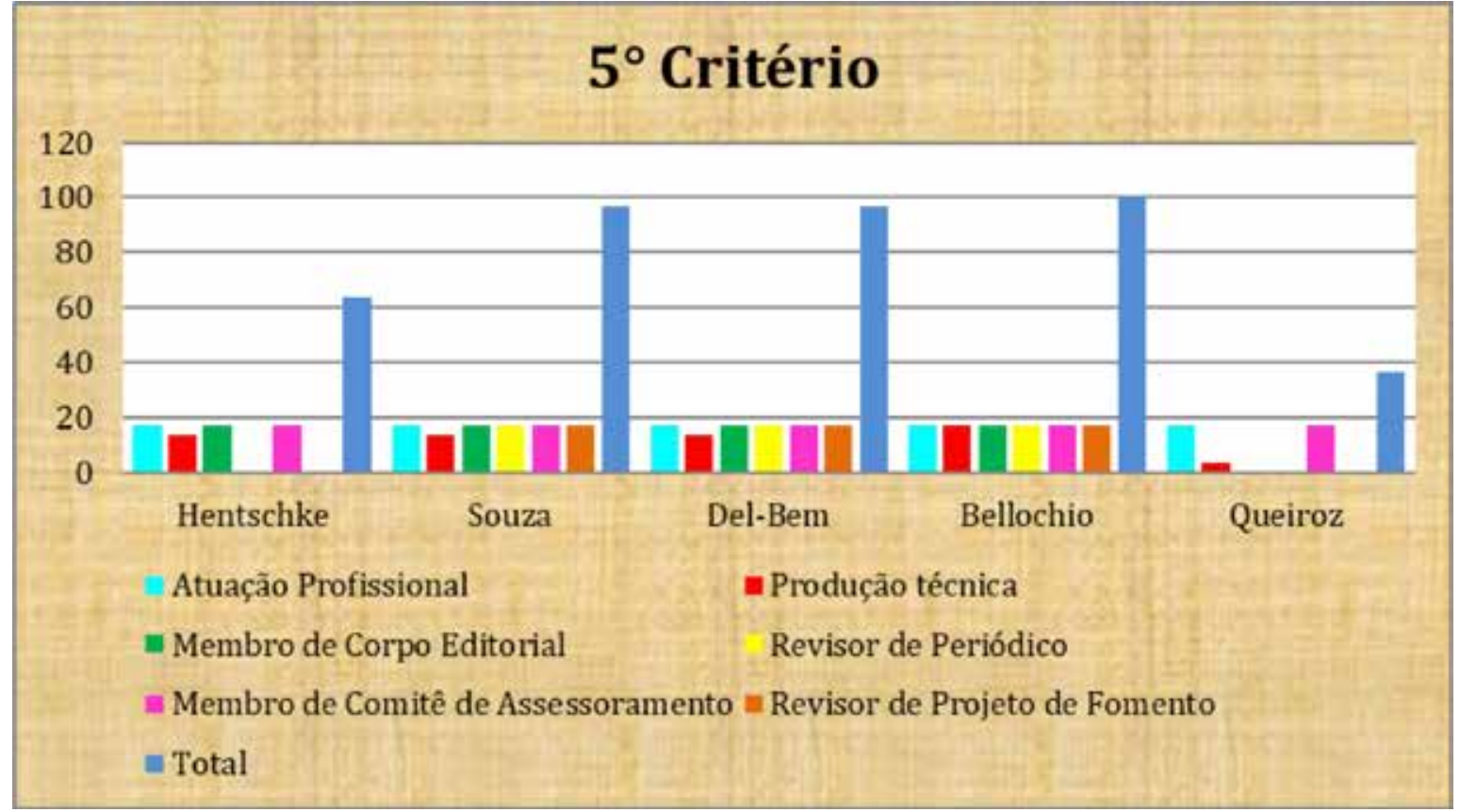

Fonte: elaborado pelo autor.

Percebem-se nesse critério fragmentos de uma vida inteira, aqueles eventos importantes que marcam determinadas épocas e lugares que acabaram por construir a trajetória de vida-científica dos pesquisadores como sujeitos do meio, do lugar em que estão inseridas suas reflexões epistemológicas.
Portanto, as trajetórias são questões sociológicas em que os pesquisadores construíram seus percursos biográficos cujos caminhos estiveram ligados ao social. O social aqui é o contexto em que coexistem o eu profissional e o seu eu pessoal, ou seja, um paralelo que converge de um ser para um am- 
plo contexto repleto de interconexões. Os resultados em forma de conhecimento gerado dessas trajetórias de vida-científicas convergem para a sociedade. Isso mostra mais uma vez a importância dos pesquisadores para as mais distintas áreas no país. A partir dessas reflexões empreendidas até o momento, subentende-se que foram as trajetórias desses pesquisadores - como sujeitos do meio, do lugar que estão inseridos e suas reflexões epistemológicas - que ajudaram na consolidação da área da Educação Musical como conhecemos hoje.

\section{Configuração da trajetória de vida-científica mediante a valoração do biograma}

o biograma é um dispositivo inovador cujo preenchimento deu-se a partir de cinco critérios do CNPq. O processo de análise ocorreu com base na teoria da hermenêutica, buscando a valoração para explicar os resultados implícitos, tornando o biograma um referencial teórico-metodológico. Tais aspectos configuram-no na própria trajetória de vida-científica.

Com tais primícias, foi possivel estabelecer configurações e fluxos das trajetórias de vidacientífica dos pesquisadores $P Q$ s como causa e efeito para a configuração e um panorama da Educação Musical brasileira.

A proposição formativa pela vertente das trajetórias de vida-científica dos pesquisadores da Educação Musical está relacionada com a concepção da unicidade dessas vidas científicas, e isso mostra como esse campo vem se configurando ao longo dessas três décadas. Tal panorama é resultante dos biogramas que mapearam as trajetórias de vida-científica dos cinco pesquisadores. Ou dito de outro modo, a configuração da trajetória de vida-científica se deu mediante a valoração no biograma elaborado a partir do Currículo Lattes.
Com essas trajetórias de vida-científica, é possivel compreender como os cinco pesquisadores consolidaram suas carreiras. Essa consolidação veio através: de estudos no Brasil e no exterior; pela busca por excelência acadêmica; como fundadores da associação que representa a área, $A B E M$; por suas publicações contínuas de artigos, capítulos de livros e livros que são referências bibliográficas nos estudos da área na graduação e em PPGs no Brasil; pelo destaque como formadores de pesquisadores e coordenadores de grupos de pesquisa nos PPGs nas instituições que estão vinculados e pela participação e organização de eventos - seminários, congressos, encontros, convenções, conferências - nacionais e internacionais na área, nesse caso, a Educação Musical, com destaque para eventos da Sociedade Internacional para Educação Musical (ISME), ABEM e da Associação Nacional de Pesquisa e Pós-graduação em Música (ANPPOM).

A essência correspondente dessas trajetórias revela uma conexão que parece apontar para um objetivo, um propósito, dando assim, a meu ver, harmonia a essas vidas-científicas e por isso, as necessidades em comum de área foram obtidas.

Nisso, destaca-se a ação coletiva nos projetos de pesquisa ou em coautoria que contribuem para pensar a Educação Musical a partir de diferentes olhares que, em determinados momentos, se completam colaborando para o amadurecimento do campo investigativo da área. 0 enfoque pretendido dessa ação parece estar na interação ao promover essas mudanças estruturais, outro elemento prioritário dos cinco pesquisadores mostrado pelos biogramas. Essas trajetórias singulares-universais de pesquisadores da área continuam a contribuir com a construção da história da Educação Musical brasileira.

O biograma mostrou que, ao construir seus caminhos, houve, portanto, fragmentos de 
uma vida inteira, aqueles eventos importantes que marcam determinadas épocas e lugares que acabaram por construir a trajetória de vida-científica. E, ainda, que nessas trajetórias de vida-científica existe algo que os une.

As diversas ideias dos autores supramencionados foram fundamentais para a construção dos conceitos de biograma e trajetórias de vida-científica, apresentados na introdução. Construo, a seguir, as notas finais para trazer compreensões sobre esse referencial teóricometodológico que é o biograma.

\section{À guisa de ilação}

A trajetória de vida-científica traçada por meio do biograma aqui delineado é um novo tipo de instrumentalizar metodologicamente para um modo de se fazer pesquisa. 0 foco deste texto, portanto, foi apresentar um novo formato de biograma e sua utilização na pesquisa como referencial teórico-metodológico.

o biograma expressa as dimensões que partem da figura do pesquisador como sendo o centro que se expande para organismos mais abrangentes. Tal fato parte do micro para o macro, ou/ e vice-versa; essa é a relação. Isso consiste no pensamento biosistêmico ${ }^{5}$.

As trajetórias de vida-científica são singulares-universais; se expressam individualmente únicas, embora se complementem em sua relação com sua área de conhecimento. A trajetória de vida-científica é uma manifestação particular de um indivíduo cujo propósito é a inserção em seu tempo, no lugar, em sua área, ou seja, em sua realidade concreta, no campo de saber científico em que vive.

A metodologia utilizada neste trabalho foi de natureza qualitativa, com base na pesquisa documental cuja fonte incide sobre o Currículo

5 Hábito diário das ações torna-se no pensamento biosistêmico, cujo foco são as interações internas e externas, ou seja, dinâmicas vitais presentes nas organizações, mas que parte do indivíduo.
Lattes. Para Barbosa e Passeggi (2011), história de vida é tanto teoria quanto metodologia. Isso levou a compreensões de que a trajetória de vida-científica aqui desenvolvida é tanto a teoria quanto a metodologia. o biograma foi o referencial teórico-metodológico e pode ser utilizado nas mais diversas áreas do conhecimento. Teórico por trazer o conceito de biograma para o campo da Educação Musical, e metodológico por ser o instrumento usado para a construção das trajetórias de vida-científica. Os resultados apontaram que o biograma é sinônimo de trajetória de vida-científica.

Para elaborar a trajetória de vida-cientifica, um novo formato de biograma foi desenvolvido com os critérios do CNPq para atender aos objetivos da pesquisa empreendida. As trajetórias de vida-científicas são descritivas e estão caracterizadas no biograma. Essa caracterização parte, num primeiro momento, da reflexão do pesquisador em suas produções e avanços para a área.

Ao observar, nos biogramas, as trajetórias de vida-científica dos cinco pesquisadores $P Q s$, a partir das categorias que emergiram do CNPq, foi possivel mensurar, sob um dos vários aspectos, o desenvolvimento profissional da área. A síntese da área encontra-se no conjunto de trajetórias de vida-científica dos pesquisadores PQs da Educação Musical, e, nessa sintese, uma afirmação identitária da área como ciência pela maturidade de suas vidascientíficas.

0 que emerge dessas trajetórias de vidacientífica pelo biograma revela como a área vem se delineando ao longo de sua história, e permite enxergar os processos de formação intelectual e profissional, tanto individual quando coletivo que se mesclam com outras áreas do conhecimento. Por isso, a importância da visibilidade das trajetórias de vida-científica apresentada pelos biogramas dos pesquisadores. Os resultados dos dados coletados e aqui 
tratados nos biogramas se caracterizam como uma maneira de mostrar, pelas trajetórias de vida-científicas, um aspecto das várias histórias da Educação Musical brasileira.

O impacto dos Currículos Lattes, dos biogramas e, consequentemente, das trajetórias de vida-científica reside em um ponto que é o "paradoxo epistemológico fundamental das autobiografias: a união do mais pessoal com o mais universal" (FERRAROTTI, 1988, p. 27).

Ao (re)fazerem os pensamentos e ações, há uma retroalimentação de ideias, reflexões, saberes, ações para si e para a sociedade. Isso se consolida para o campo de estudo: a área da Educação Musical. Nos biogramas, é verificável a relação em partes, mas também no todo. São interações de mão dupla, em que o todo só subsiste com o sujeito (pesquisador) como base, como organismo menor, sendo este o centro para um organismo maior.

Na síntese agregadora de toda a pesquisa, buscamos elucidar, pelos biogramas, que as trajetórias de vida-científica se configuram pela unidade na diversidade de uma construção coletiva de área. É, portanto, nessa unicidade da diversidade que se localizam as premissas fundamentais da área. 0 entendimento de um campo investigativo começa pelas trajetórias de vida-científica de seus pesquisadores. Dito de outro modo, as trajetórias de vida-científica se constituem como um produto advindo do conhecimento cumulativo, gerado com os efeitos vividos, praticados, que formam, dão forma e (com)formam o campo da Educação Musical. Nisso, reside a importância do biograma como referencial teórico-metodológico.

Portanto, acreditamos que este artigo poderá contribuir para novos estudos em várias vertentes. Uma dessas vertentes está direcionada às histórias de vida de pesquisadores da Educação Musical, pelo fato deste estudo estar atrelado ao projeto guarda-chuva de Abreu (2016) denominado “Educação Musical e Pesquisa (Auto)Biográfica - Desafios epistemológicos". Esse projeto consiste em acolher estudos e pesquisas em Educação Musical com o objetivo de "escolher, intencionalmente, educadores musicais que têm se sobressaído como profissionais que influenciaram e vêm influenciando comunidades e gerações escrevendo a História da Educação Musical no Brasil" (ABREU, 2016, p. 7).

É notório um avanço nessa perspectiva em se tratando de histórias de vida com a Educação Musical. É um paralelo indivisível uma vez que ter uma história de vida com a Educação Musical significa dizer que o sujeito "participa da construção da área, mas também constrói a sua própria história de vida com a área" (ABREU, 2019). Espera-se que esta pesquisa gere acervos para utilização de estudiosos da área em pesquisas futuras.

\section{Referências}

ABREU, Delmary Vasconcelos. A construção da educação musical no Distrito Federal e história de vida de educadores musicais. Projeto de pesquisa (Projeto universal CNPq 2016 a 2019) Programa de PósGraduação em Música, UnB, DF. 2016.

ABREU, Delmary Vasconcelos. A construção da educação musical no Distrito Federal: histórias de vida na perspectiva epistêmico-metodológica. In: ABRAHÃO, Maria Helena Menna Barreto. (Org.). Atos de Biogr@far: narrativas digitais, história, literatura e artes. Curitiba: CRV, 2018, p. 265-285.

ABREU, Delmary Vasconcelos. A história de vida aguçada pelos biografemas: um recorte da história de Jusamara Souza com o campo da educação musical. Revista da Abem, v. 27, n. 43, p. 150-167, jul./ dez. 2019. Disponivel em: http://www.abemeducacaomusical.com.br/revistas/revistaabem/index. $\mathrm{php} / \mathrm{revistaabem/article/view/856.} \mathrm{Acesso} \mathrm{em:} 17$ fev. 2020.

AGRA, Cândido da; MATOS, Ana paula. Trajectórias

Desviantes. Lisboa: Droga (1997). 
BONDÍA, Jorge Larrosa. Notas sobre a experiência e o saber e o saber de experiência. Revista Brasileira de Educação, Vol. 19, p. 20-28, Jan-Abr, 2002. Disponivel em: https://www.scielo.br/scielo.php?pid $=s 1413-24782002000100003 \&$ script $=$ sci_abstrac t\&tlng=pt. Acesso em: 21 fev. 2020.

BOGDAN, Robert. C; BIKLEN, Sari Knopp. Investigação qualitativa em educação: uma introdução à teoria e aos métodos. Trad. Maria J. Alvarez; Sara B. dos Santos; Telmo M. Baptista. Porto: Porto Editora, 1994. (Coleção Ciências da Educação).

BARBOSA, Tatyana Mabel Nobre; PASSEGGI, Maria da Conceição (org.). Memorial acadêmico: gênero, injunção institucional, sedução autobiográfica. Natal: EDUFRN. 2011. 214 p. (Coleção pesquisa (auto)biográfica e educação. Série Escritas de Si).

BELLOCHIO, Cláudia. Da produção da pesquisa em educação musical à sua apropriação. OPUS, [s.l.], v. 9, p. 35-48, dez. 2003. Disponivel em: https://www. anppom.com.br/revista/index.php/opus/article/ view/86. Acesso em: 19 fev. 2020.

BOLIVAR, Antonio; DOMINGO, Jesús; FERNÁNDEZ, Manuel. La investigación biográfico-narrativa en educación enfoque y metodología. Ed. Muralla. 2001.

BRASIL. Lei no 11.769, de 18 de agosto de 2008. Altera a Lei no 9.394, de 20 de dezembro de 1996, Lei de Diretrizes e Bases da Educação, para dispor sobre a obrigatoriedade do ensino da música na educação básica. Diário Oficial da União, Brasília, DF, ano CXLV, n. 159, de 19 ago. 2008, Seção 1, p. 1.

CONSELHO NACIONAL DE DESENVOLVIMENTO CIENTíFICO E TECNOLÓGICO (CNPq). Chamada CNPq N o 06/2019 - Bolsas de Produtividade em Pesquisa. Disponivel em: http://www.cnpq.br/web/guest/ chamadas-publicas?p_p_id=resultadosportlet_ WAR_resultadoscnpqportlet_INSTANCE_0ZaM\&filtro=abertas \&detalha=chamadaDivulgada\&idDivul gacao=8722. Acesso em: 5 ago. 2020.

CONSELHO NACIONAL DE DESENVOLVIMENTO CIENTÍFICO E TECNOLÓGICO (CNPq). Produtividade em Pesquisa - PQ. 2018. Disponível em: http://www.cnpq. br/documents/10157/5f43cefd-7a9a-4030-945e -4a0fa10a169a. Acesso em: 3 fev. 2018.
CONSELHO NACIONAL DE DESENVOLVIMENTO CIENTífICO E TECNOLÓGICO (CNPq). Bolsas. 2017. Disponível em: http://cnpq.br/apresentacao13/. Acesso em: 28 ago. 2017.

CONSELHO NACIONAL DE DESENVOLVIMENTO CIENTíFICO E TECNOLÓGICO (CNPq). Disponivel em: http://cnpq.br/view/- / journal_content/56_INSTANCE_0oED/10157/2958271?COMPANY_ID=10132. Acesso em: 28 ago. 2017.

CONSELHO NACIONAL DE DESENVOLVIMENTO CIENTíFICO E TECNOLÓGICO (CNPq). COCHS | AC - Artes, Ciência da Informação, Museologia e Comunicação. 2014. Disponivel em: http://cnpq.br/ web/guest/view/- / journal_content/56_INSTANCE_0oED/10157/47778. Acesso em: 28 out. 2018.

DEL-BEN, Luciana Marta. A pesquisa em educação musical no Brasil: breve trajetória e desafios futuros. Per Musi (UFMG), Belo Horizonte, v. 7, p. 76-82, 2003. Disponivel em: http://musica.ufmg.br/permusi/permusi/port/numeros/07/num07_cap_06.pdf. Acesso em: 13 jan. 2020.

DEL-BEN, Luciana Marta. (Para) Pensar a pesquisa em educação musical. Revista da ABEM, Porto Alegre, v. 24, p. 25-33, set. 2010. Disponível em: http:// www.abemeducacaomusical.com.br/revista_abem/ ed24/revista24_artigo3.pdf. Acesso em: 1o fev. 2020.

DEL-BEN, Luciana Marta. Políticas de ciência, tecnologia e inovação no Brasil: perspectivas para a produção de conhecimento em educação musical. Revista da ABEM, Porto Alegre, v. 32, p. 130-142, janjun. 2014. Disponivel em: http://www.abemeducacaomusical.com.br/revistas/revistaabem/index. $\mathrm{php} / \mathrm{revistaabem/article/view/467.} \mathrm{Acesso} \mathrm{em:} 14$ fev. 2020.

DEL-BEN, Luciana Marta. Políticas de ciência, tecnologia e inovação no Brasil: perspectivas para a produção de conhecimento em educação musical. Revista da ABEM, v. 22, p. 130-142, 2014. Disponivel em:http:// www.abemeducacaomusical.com.br/revistas/revistaabem/index.php/revistaabem/article/view/467. Acesso em: 14 fev. 2020.

DEL-BEN, Luciana Marta. Mesa Redonda: Produção de conhecimento em Educação Musical na América 
Latina. In: Conferência regional latino-americana da ISME, 11.,2017, Natal, Escola de Música da UFRN. 8 a 11 de agosto de 2017. Disponivel em: https: / / www.facebook.com/isme.natal/videos/137695230165945/. Acesso em: 10/ 01/2020.

DROESCHER, Fernanda Dias; SILVA, Edna Lucia da. O pesquisador e a produção científica. Perspect. ciênc. inf. Belo Horizonte, v. 19, n. 1, p. 170-189, março de 2014. Disponível em: http://www.scielo.br/scielo.php?script=sci_arttext\&pid=S141399362014000100011\&lng=en\&nrm=iso. Acesso em: 15 jun. 2019.

FERRAROTTI, Franco. Sobre a autonomia do método biográfico. In: NÓVOA, A; FINGER, M. 0 método (auto) biográfico e a formação. Lisboa: Ministério da Saúde, 1988. p. 17-34.

FIGUEIREDO, Sérgio; SOARES, José; SCHAMBECK, Regina Finck (Orgs.). The Preparation of Music Teachers: a Global Perspective. Porto Alegre: ANPPOM, 2015.

FIGUEIREDO, Sergio; SOARES, José. A formação do professor de música no Brasil: desafios metodológicos (completo). In: XIX Congresso Anual da ABEM, 2010, Goiânia. Anais [...]. XIX Congresso Anual da ABEM. Goiânia: ABEM, 2010. v. 1. p. 187-196. Disponível em: https://grupodepesquisamuse.files.wordpress. com/2015/04/ebook-a-formacao-do-professor-demusica-no-brasil.pdf. Acesso em: 15 fev. 2020.

FIGUEIREDO, S. L. F.; SOARES, J. Desafios para a implementação metodológica de pesquisa em larga escala na educação musical. Opus (Belo Horizonte. Online), v. 18, p. 257-274, 2012. Disponível em: https: / / www.anppom.com.br/revista / index.php/ opus/article/view/185. Acesso em: 15 fev. 2020.

GIL, Antonio Carlos. Como elaborar projetos de pesquisa. 4. ed. São Paulo: Atlas, 2008.

LEITE-OLIVEIRA, Raimundo Vagner. Trajetórias de vida-científica dos cinco pesquisadores/PQ do CNPq da educação musical: a construção de biogramas a partir de fontes documentais. 2019. 204 f., il. Dissertação (Mestrado em Música)-Universidade de Brasília, Brasília, 2019. Disponível em: https: / / repositorio. unb.br/handle/10482/35884. Acesso em: 1 fev. 2020.
LÜDKE, M.; ANDRÉ, M.E.D.A. Pesquisa em educação: abordagens qualitativas. São Paulo, EPU, 1986.

MANITA, C. Evolução das significações em trajetórias de droga-crime (II): Novos sentidos para a intervenção psicológica com toxicodependentes? Toxicodependências, 7(3), p. 59-72. 2001. Disponivel em: https://repositorio-aberto.up.pt/bitstream/10216/6882/2/82679.pdf. Acesso em: 14 fev. 2020.

NASCIMENTO, Juliana Luporini do; NUNES, Everardo Duarte. Quase uma auto/biografia: um estudo sobre os cientistas sociais na saúde a partir do Currículo Lattes. Ciênc. saúde coletiva, Rio de Janeiro , v. 19, n. 4, p. 1077- 1084, Apr. 2014. Disponível em: https://www.scielo.br/scielo.php?pi$d=$ S1413-81232014000401077\&script=sci_abstrac t\&tlng=pt. Acesso em: 13 fev. 2020.

OLIVEIRA, Alda. ABEM: 20 anos de construção coletiva para a consolidação do ensino de música no Brasil. Revista da ABEM, Londrina, v. 20, n. 28, p. 15-26. 2012. Disponível em: http://www.abemeducacaomusical.com.br/revistas/revistaabem/index. $\mathrm{php} / \mathrm{revistaabem/article/view/100}$. Acesso em: 10 fev. 2020.

PRODANOV, C.C; FREITAS, E.C. Metodologia do trabaIho científico: Métodos e Técnicas da Pesquisa e do Trabalho Acadêmico. 2a ed. Universidade Feevale Novo Hamburgo, Rio Grande do Sul, 2013.

SOUZA, Jusamara Vieira de. et al. Audiência Pública sobre políticas de implantação da Lei Federal no 11769/08 na Assembleia Legislativa do Rio Grande do Sul. Revista da ABEM, Porto Alegre, v. 23, p. 8494, mar. 2010. Disponível em: http:/ / www.abemeducacaomusical.com.br/revistas/revistaabem/index. $\mathrm{php} / \mathrm{revistaabem/article/view/219}$. Acesso em: 10 fev. 2020.

SOUZA, Jusamara Vieira. Contribuições teóricas e metodológicas da Sociologia para a pesquisa em Educação Musical. In: ENCONTRO ANUAL DA ABEM; SIMPÓSIO PARANAENSE DE EDUCAÇÃO MUSICAL, 5., 1996, Londrina. Anais [...]. Londrina, 1996a. p. 11-39.

SOUZA, Jusamara Vieira. Inovação em educação musical: reflexões para as práticas de ensino de mú- 
sica. In: Luiza Botelho Albuquerque; Pedro Rogério; Marco Antônio Toledo Nascimento. (Org.). Educação Musical: reflexões, experiências e inovações. Fortaleza: Edições UFC, 2015, v. 1. p. 23-44.

SOUZA, Jusamara Vieira. Pensar a educação musical como ciência: a participação da ABEM na construção da área. Revista da ABEM, Porto Alegre, n. 16, p. 25-30, mar. 2007. Disponivel em: http:/ / www.abemeducacaomusical.com.br/revistas/revistaabem/index.php/revistaabem/article/view/288/218. Acesso em: 3 fev. 2020.

SANTOS, Regina Marcia Simão. A Universidade Brasileira e o Projeto Curricular dos Cursos de Música frente ao panorama Pós-Moderno., Revista da
ABEM. Porto Alegre, n. 8, p. 63-68. 2003. Disponivel em: http://www.abemeducacaomusical.com.br/ revistas/revistaabem/index.php/revistaabem/article/view/418. Acesso em: 3 mar. 2020.

VELOSO, Rita C. L. A questão do método na hermenêutica filosófica de H.-G. Gadamer. In: BRITO, Emídio Fontenele; CHANG, Luiz Harding (Org.). Filosofia e método. São Paulo: Loyola, 2002. p. 89-111. (Coleção CES) WITTER, Geraldina Porto. Produção científica. Campinas, SP: Editora Átomo, 1997.

Recebido em: 04/05/2020 Revisado em: $12 / 08 / 2020$ Aprovado em: 10/08/2020

Raimundo Vagner Leite de Oliveira possui mestrado em Música pela Universidade de Brasília (UnB). Participa do Grupo de Pesquisa Educação Musical Escolar e Autobiografia (GEMAB) da UnB. É organizador da série "Educação em Foco", autor do livro "Trajetória de Vida-Científica na Educação Musical" e avaliador ad hoc de dois periódicos científicos (UFT e UFSC). Foi professor substituto na Universidade Federal do Tocantins (UFT).E-mail: raimundo.vagner@mail.uft.edu.br 